\title{
Chinese Traditional Sports thoughts about keeping in good health and its Modern Value of Health Research
}

\author{
Zhong HAN \\ Weifang University of Science and Technology \\ Shouguang,Shandong,262700 China
}

\begin{abstract}
Chinese traditional sports regimen is established on the basis of traditional Chinese culture, it is a traditional sports item. It is a product of the traditional Chinese culture and the social sciences two-way interaction in specific social and historical conditions; it is academic frontier research in the field of Chinese traditional sports. However, fewer sectors will develop the traditional Chinese regimen and place it under the entire background of traditional Chinese culture to conduct a comprehensive review, ignoring that Chinese traditional culture has a comprehensive and systematic research to the health system of Chinese sports thought patterns. In addition, in recent years, the academic research in the field of health at home and abroad is mainly in health history literature, the origin, development and health function, its perspective focused mainly on "health history" of traditional Chinese culture, which is not enough in digging the intrinsic the modern meaning of traditional Chinese culture .
\end{abstract}

Keywords-Chinese national traditions, physical regimen, modern cultural values

\section{INTRODUCTION}

In the long history and splendid civilization of the Chinese nation, the sports culture of health exudes light timelessly with its unique charm and spread up to now. However, with the influence of special historical circumstances, the field of sports focus more on the development of competitive sports, while pay less attention to other traditional sports such as physical regimen, for instance, Sports College, who trained health personnel has always been using the main power of traditional national sport to train the professional martial arts teachers and coaches, which led to the over general development of the traditional national sport, the whole country is only concerned about competitive martial arts, while traditional martial arts, sports and health cares have got few attention, sports and health professionals are scanty, which severely restricted the inheritance and development of sports and health culture.

With the rapid development of society and the rapid development of technology, the Chinese people's living standards have got greatly improved. These bring convenience, but it also brings a variety of diseases of civilization." Thus, people begin to pay attention to their own health. Physical health exercises, such as guided massage technique, Qigong and other cardiac achieve fitness, are helpful for health through internal and external alike and the body's own way of conditioning, the effect is remarkable, scientific and healthy. Thus physical regimen gets people's concerns increasingly. And in times that Eastern and Western cultures collide so often, more and more overseas scholars began to notice China's sports health culture in order to inherit and develop the national spirit and reflect the characteristics of the Chinese nation, promoting the historic heritage of sports and health culture become one of the important ways. Thus, in recent years, the development strategy of China's sports has gradually changed; reform of higher education continue to deepen, advanced Sports College change primary professional martial arts to traditional and folk sports includes martial arts, sports and health. But it is still a blank on sports talent cultivation, thus, traditional national sports open the course of physical regimen to meet the needs of the community, which has become paramount affairs.

\section{CONCEPT OF TRADITIONAL SPORTS REGIMEN}

Currently, there is a variety of discussion on definition of "traditional sports health", for example, Gai Jianwu said: "The Chinese traditional sports regimen is a traditional health science, as a product of the interaction between science and the human body, it is a special health system gradually developed in order to solve their basic problems of life and death in traditional Chinese culture and the process of interacting with each other around its world outlook, outlook on life and values of traditional Chinese. "Another example is Zhang $\mathrm{Li}$, she look "traditional sports" as " summary of the theories and methods of human health based on long-term experience and labor practices of working people and intellectuals, its content is rich, involving diet, living, work and rest, guidance, emotional, etc., the principle of followed conform placed to keep practicing; proactive precautionary principle and the principle of combining hardness with softness, static and dynamic binding, and it obtains philosophy of traditional Chinese culture and wisdom of life, "Professor Hu Xiaofei said it is "blowing Calls breathing exercises and similar, if the rain kept the idea of activity as the basic means of self-training from the basic means of health and feature."

Obviously, the three definition of "traditional sports health" are just described and explained in terms of cultural 
background empirically, principles of health, health methods, which is far from revealing its essence connotation.

Currently, the definition of "traditional sports" in "Chinese traditional sports health science", Professor Qiu Wangxiang editor-in- chief, is identified by academic circle: "Through the body's own posture adjustment, breathing exercises, mind control to integrate mind and body to achieve enhanced performance, inspire the human body induction and the inherent potential, play a important role on against the disease, puzzle and sickness. " the concept basically summed up the essence of the meaning of traditional sports and health in terms of essential connotation, functional orientation and value orientation, but in the cultural context, the concept of outreach aspects need to be further improved.

In summary, this article defined "traditional sports" as: based on the theoretical foundation of traditional Chinese life sciences, shaped by the body's own tone, breathing, tone god, to improve the lives of the degree of coordination, and enhance the lives and health level, prolong life, the life inherent potential to induce physical exercises and body movement as the main form of the theory and techniques of health systems. Its outreach includes breathing, qi, guidance, massage, static stance, Yi Jin Jing, Wu Qin Xi, Liu Zi Jue, Ba Duan Jin, tai chi and so on.

\section{THE PHILOSOPHY THOUGHTS OF CHINESE HEALTH SPORTS}

Chinese health sports, in the formation and development process, continue to absorb and apply some of the important thinking of the time, mainly in the following areas.

\section{A. Yin and yang}

Yin and Yang is a category of ancient Chinese philosophy. This is used in medicine and health, to explain human body as an organic integrity, its all organizational structure are both organic connective and can be divided into two parts: yin and yang. Such as: the internal of body is yin, the internal of body is yang; the lower part is yin, the upper part is yang; stomach is yin, back is yang; internal organs are yin, the six fu-organs are yang; substance is yin, function is yang; suppression is yin, excitement is yang. Among these organs, heart, lungs lie in chest, it belongs to yang, spleen, liver, and kidney lie in peritoneal and it belongs to yin. Each viscus can be divided into yin and yang; such as heart has yin and yang, kidney has yin and yang and so on.

Chinese health science believes that the body's opposition over this yin and yang is relative, separable, mutual roots, can be mutual transformed and constrained. Therefore, the "neijing" said yin and yang balance within the human body and the surrounding environment means human health, the destruction of the balance means sick. All different kinds of diseases, the body's yin and yang are inconsistent with performance, and all health, treatment methods focus on restoring and maintaining the body's yin and yang balance.

\section{B. The five elements}

The five elements is also an ancient philosophical thought. Chinese health sages classified according to the characteristics of the five elements to explain the physiological function of internal organs. Such as: the five elements of wood, of right and wrong, hi reached, each of the outer stretch upward; internal organs of the liver, likes strip of sparse smooth, curb depression evil, showing features to clear the open vent, so the liver is wood. Soil of the five elements, is honest and simple to carry everything; internal organs in the stomach are fit for dissolving Water Valley and providing subtle substance to nourish organs. As can be seen above, Chinese health sports are based on the ancient Chinese philosophy in the formation and development process; it has a very close relationship with the ancient Chinese philosophy. So, some people say Chinese health sport is "Philosophy Sports", these words are justified.

\section{MEETING POINT OF CHINESE TRADITIONAL SPORTS CULTURE AND MODERN SOCIETY}

The Development of modern society manifested prominently in which the development of modern science and technology provide mankind with the creation of wealth and the ability and means to sustainable development; which had an important influence on humanity scientific world outlook and methodology and it had a significant impact on the improvement of human awareness level, causing a profound change in the modern way of thinking; greatly promoted the improvement and development of labor productivity, so that manual work transform to brainwork.

From the perspective of the development of cultural history, in every step, human creative activities are relying on the culture and affected by it. Cultural development can bring human civilization and progress, and humanity barbarism and ignorance also; it not only brings rationality to humans, but also bring irrational to humans. From barbarism to civilization, Mankind relied on the progressive culture; from the biological to the community of people relied on cultural enlightenment. People vary widely in personality, temperament, character, style due to cultures and cultural life and existence value, are inseparable from culture. So, we will measure the degree of social progress according to a variety of human cultural development.

In modern society, people are no longer satisfied merely to pursue the kind of excitement and fanatic atmosphere game-winning sports; they need a high level of physical and mental experiences and emotional activities. The update of human health sports culture and entertainment outlook make mass sports activities bloom. The demand for sports entertainment and fitness activities is more urgent, the scale is increasingly broad. Ascendant mass sports, is becoming a modern lifestyle content to improve the quality of life of people. There is a growing emphasis on the unity of the physical and mental health concepts, and thus emphasis on physical and mental health and spiritual development of Chinese traditional sports culture. Thus, in modern society, people urgently demand for cultural sports and health, especially the traditional Chinese culture in the form of national sport in China nourishing for thousands of years, contains a rich cultural colors, it is a high level of cultural phenomenon. Historically, its traditional cultural connotation inspired generations of people to meet the needs of different 
societies, the development of the society has played an important role. Now some of the traditional health culture and ideology of cultural contents ethics, philosophy, fitness and other aspects of modern society and culture of the people, this demand has an unprecedented breadth and depth of the intersection and integration, which is the needs fit for culture in the modern society, people can learn from the idea of the essence to guide their behavior.

\section{MODERN VALUE OF CHINESE TRADITIONAL SPORTS REGIMEN}

Traditional sports health science focus on the development and improvement of life of the individual, it looks the individual's success as a basis for social progress, science reveals the nature of man and lays the scientific foundation for the establishment of a "people-oriented" thinking. Adhered to the people-oriented and promoted the comprehensive development of man, are not only concentrated expression of the essence of socialism, but also pursued the goal of the traditional sports regimen, traditional sports health science emphasis on "your own", "rebirth", advocating transform individual from the reality of life, and exert influence on the social environment through individual behavior. Traditional sports regimen can effectively reduce people's medical costs, alleviate social contradictions. Unlike traditional sports to pursue the ultimate of human body, physical regimen pursuing relatively soothing exercise and appropriate exercise can well act as a "cure, no disease prevention" effect.

Traditional Sports Health is an important part of national fitness campaign, it can effectively promote rapprochement between people. Traditional sports physical and mental health in pursuit of the principle of balanced development, focusing on healthy relationships between human psychology and physiology, focusing on the harmonious relationship between man and the environment, man and nature, between people, in line with the Chinese people's way of thinking, the principle of doing things and aesthetic requirements, naturally occupies an important corner of the fitness movement. Traditional sports health requires smooth mood, inaction and focused on increasing self-restraint and individual improvement which can effectively promote rapprochement between people.

Traditional Sports Health is the foundation of harmonious society. Harmonious society mainly requires harmonious people, who can get the smoothest situation under the state of peace; they can get the most desirable development. Through traditional sports health, People learn how to cultivate peace in Life and obtain social peace. In the process of traditional health practices, that is, from one's own peace enter into the peace of man and nature. Cultivating the moral spirit must get rid of evil and develop right things, coordinate good and evil and boost righteousness.

\section{CONCLUSIONS}

Chinese Traditional Sports Health holds that through emotional regulation, balance of yin and yang, ideas, guidance, and other ways, we can get special way to promote human health, under the guidance of the theory of traditional Chinese sports health, long-term engaged in exercises can not only make people in the process, but in the course of their daily work and life, correct attitude towards life, when they are working actively, they are indifferent to fame and fortune, laugh at life's successes and failures, and gradually have generous, kind and open minds, they can improve the body's ability to resist the fierce competition brought by the pressure, but also enable people to effectively avoid and overcome the negative effects of modern society on human health. In addition, the practice of traditional sports and health can receive good preventive and therapeutic effects for sub-health, chronic diseases. Thus, the traditional Chinese concept of health is one of the major sports to ensure the sustainable development of modern society; it is a valuable wealth to the improvement of human health life in modern society, so the concept of Chinese traditional sports regimen is adapted to suit the modern regimen and it is fit for Modern science.

\section{REFERENCES}

[1] Chen Lianzhen. Chinese traditional sports and the modern modes of thought and cultural value of health research [D]. Southwest Normal University, 2005.

[2] Gai Jianwu. Chinese traditional sports mode of thinking and its modern value health research [J]. Sports Culture Guide,2004,08:3940.

[3] Kang Dejiang. Philosophy of traditional sports and cultural health of the [D]. Shanghai Institute of Physical Education, 2010.

[4] Qianhongjun. Comparative Study of Chinese traditional sports [D] and the modern physical fitness. Suzhou University, 2012.

[5] Dengyue Fei, Li Wei. modern value of traditional sports and health research. [J]. Bo hit (Martial Science),2006,12:73-74.

[6] Sun Hui, Niyike. Traditional Culture in Modern Leisure concept [J]. Sports Culture Guide,2007,01:58-60. 